\title{
CONHECIMENTO E APRENDIZAGEM HISTÓRICA: TENSÕES ENTRE AS PERSPECTIVAS DA TRANSPOSIÇÃO DIDÁTICA E DA LITERACIA HISTÓRICA A PARTIR DA EXPERIÊNCIA DE PROFESSORES
}

\author{
KNOWLEDGE AND HISTORICAL LEARNING: \\ TENSIONS BETWEEN THE PERSPECTIVES OF THE DIDACTIC \\ TRANSPOSITION AND OF HISTORICAL LITERACY BASED ON TEACHERS' \\ EXPERIENCE
}

André Luiz Batista da Silva ${ }^{1}$

\begin{abstract}
RESUMO: O presente estudo origina-se de investigação realizada no Programa de Pós-Graduação em Educação da Universidade Federal do Paraná nos anos de 2010 e 2011. O estudo tem como premissa discutir e explicitar as tensões existentes na aprendizagem histórica no contexto escolar entre as perspectivas didáticas da transposição didática e da literacia histórica. Para tanto, investigou-se que concepções de aprendizagem da histórica possuem professores dessa disciplina e se tais tensões apresentam-se em seus relatos. Os resultados indicam que as concepções de aprendizagem histórica dos professores investigados contêm elementos tanto da transposição didática quanto da literacia histórica, evidenciando-se que essa tensão indica por um lado o conflito entre um processo de didatização da história e a sua natureza específica.
\end{abstract}

Palavras-chaves: Aprendizagem histórica. Conhecimento histórico. Transposição didática. Literacia histórica. Professores de História.

\begin{abstract}
This study has its origin in an investigation performed in the Post Graduation Program in Education of the Federal University of Paraná in 2012 and 2011. The study has as its premise to discuss and explain the tensions existing in the historical learning in the school context among the didactic perspectives of the didactic transposition and of the historical literacy. For this, we investigated what learning conceptions the teachers of this subject have and if such tensions are present in their reports. The results indicate that the conceptions of historical learning of the investigated teachers have elements both of the didactic transposition and the historical literacy. This evidenced that this tension indicates the conflict between a process of history didactization and its specific nature.
\end{abstract}

Keywords: Historical learning. Historical knowledge. Didactic transposition. Historical literacy. History teachers.

1 Mestre em Educação (UFPR), professor de História do Ensino Fundamental e Coordenador de História da Secretaria Municipal de Educação (Araucária), membro do Grupo de Professores Pesquisadores de Araucária. Professor no curso de Pedagogia da Faculdade Nacional de Educação e Ensino Superior do Paraná (FANEESP). 


\section{Introdução}

O presente artigo origina-se de dissertação de Mestrado em Educação realizada no Programa de Pós-graduação da Universidade Federal do Paraná, tendo por objeto os significados da aprendizagem histórica na perspectiva da experiência de professores de história. Desse modo, a questão que se propõe discutir nesse texto circunscreve-se a perspectivas didáticas que podem ser explicitadas sobre o conhecimento histórico e sua aprendizagem no contexto escolar sob os referenciais da transposição didática (CHEVALLARD, 2005) e da literacia histórica (BARCA, 2006; LEE, 2006). Objetivamente o que se pretende apontar são algumas tensões entre as duas perspectivas anunciadas e a aprendizagem da história a partir da experiência de professores de história. A base empírica desse texto tem como referência uma pesquisa de natureza qualitativa baseada metodologicamente na entrevista semiestruturada, fundamentada em Lessard-Hebert, Goyette e Boutin (2005) onde foram sujeitos da investigação quatro professores de história que realizam suas atividades de trabalho no Ensino Fundamental de $6^{\circ}$ a $9^{\circ}$ ano.

Assim, estrutura desse trabalho ancora-se em três pontos, sendo: o diálogo acerca do conhecimento histórico e sua aprendizagem na perspectiva da transposição didática, depois a discussão entre 0 conhecimento e aprendizagem histórica e as tensões entre os conceitos de transposição didática e literacia histórica. O terceiro ponto discute os significados do conhecimento e aprendizagem da história para professores de história em um cotejamento com a perspectiva da transposição didática e da literacia histórica.

\section{Conhecimento e aprendizagem histórica: um diálogo com o conceito de transposição didática}

A partir da compreensão de que no universo escolar a História pode ser ensinada e aprendida de formas e modos diferenciados como processos de didatização, procura-se, nesse tópico analisar a aprendizagem histórica 
tendo por referencial o conceito de transposição didática. As razões que nos conduziram à análise da aprendizagem histórica por meio do conceito de "transposição didática" (CHEVALLARD, 2005) referem-se às discussões que se têm realizado quanto à pertinência desse conceito para a definição de um saber escolar, pela sua adoção, mesmo que não explícita, em orientações curriculares e pela implicação que a adoção desse conceito traz ao ensino e aprendizagem da História.

Forquin (1993) entende que a "transposição didática" se configura em uma cultura escolar, Lopes (1999, p. 208), ao se referir ao processo transposição didática como um processo de "(re)construção dos saberes na instituição escolar", compreende-o como um movimento de apenas reprodução de saberes, preferindo com isso utilizar a ideia de "mediação didática" entendida como um processo dialético entre os saberes produzidos pela ciência e os saberes ensinados nas escolas. Entretanto, mesmo utilizando o termo "mediação didática" como uma ação que permeia os saberes da ciência e os saberes veiculados na instituição escolar, Lopes (1999, p. 218) enfatiza que devemos recusar a imagem passiva da escola como receptáculo de subprodutos culturais da sociedade e compreendê-la como uma instância socializadora e produtora de conhecimentos.

A pesquisa de Leite (2007, p. 17 e 18) com relação à produção do Grupo de Trabalho de Didática da Associação Nacional de Pesquisas e PósGraduação em Educação (ANPED) e do Encontro Nacional de Didática e Prática de Ensino (ENDIPE) aponta que poucos foram os trabalhos sobre a temática do conhecimento escolar. Para a autora, "foram sete em um total de noventa e sete trabalhos apresentados" no período que vai de 1998 a 2003. O levantamento realizado por Leite (2007, p. 17 e 18) circunscrevese às apropriações realizadas acerca de dois conceitos - 0 de recontextualização didática de Bernstein e de transposição didática - no campo do conhecimento escolar e suas produções. Segundo a autora, "esse levantamento revelou também algumas diferenças significativas nas formas de apropriação das teorizações dos autores em questão". O levantamento revelou que as teorizações de Bernstein possuem mais penetração no pensamento educacional brasileiro, tanto em termos quantitativos quanto 
qualitativos. Além da relação apurada pelo levantamento, Leite coloca que, "na maior parte dos trabalhos revisados, quando há referência ao didata francês, apenas o conceito de transposição didática é mencionado e não propriamente o modelo teórico em que se insere" (LEITE, 2007, p. 18).

Fora do recorte cronológico do levantamento realizado por Leite (2007), acerca das apropriações do conceito de transposição didática, dois trabalhos de pesquisa parecem significativos no que se refere à relação do conceito de transposição didática e a didática da História: o de Monteiro (2003), que discute tal conceito com referência à prática do ensino de História e o de Anhonr (2003), com referência aos Parâmetros Curriculares Nacionais e a didatização da História enquanto disciplina escolar.

O conceito de "transposição didática" construído por Chevallard (2005) tem seu referencial na Didática das Matemáticas e emerge a partir das apropriações realizadas por Chevallard dos escritos de Verret (1975), acerca dos tempos de estudos. Tal conceito torna-se público a partir de notas preparatórias para um curso na Escola de Verão de Didática em julho de 1982. Para Chevallard (2005), o saber escolar tem sua referência no saber acadêmico. Porém, o saber escolar, que compreende como o saber ensinado, sofre algumas deformações ou adaptações para que possa ser ensinado. Tal concepção já é evidenciada no título do seu curso de Didática das Matemáticas realizado em 1982, cujo título do seu livro é: Transposição didática: do saber sábio ao saber ensinado.

A transposição didática constitui-se de um processo pelo qual um saber científico, produzido pelas instâncias acadêmicas, para se tornar um saber ensinável no contexto escolar, deve ser transformado (CHEVALLARD, 2005).

Para explicar a relação entre o saber acadêmico e o saber a ser ensinado e justificar a existência de uma transposição didática, Chevallard (2005) propõe uma noção de "sistema didático" e de um sistema de ensino. O "sistema didático", segundo o autor, é formado por três elementos: ensinante, alunos e saber ensinado. Já o sistema de ensino abrange o "sistema didático" como "entorno imediato". Para além dos dois sistemas, Chevallard (2005) traz uma terceira instância como entorno dos dois 
sistemas - a "noosfera" que se apresenta como a instância reguladora, normativa e de legitimidade do "funcionamento didático", ou seja, a "noosfera" é quem autoriza os saberes a serem ensinados e o "funcionamento didático". Observa-se que a proposição de Chevallard (2005) para a compreensão do conceito de "transposição didática" apresenta uma relação hierárquica e diretiva, o que presume, também, uma relação de poder entre as partes - da "noosfera" ao "sistema didático". Para além da "noosfera", há, segundo Chevallard, um entorno, o qual corresponde à sociedade como um todo (CHEVALLARD, 2005, p. 10-29).

Da "noosfera" e do entorno ao interior do "sistema didático", existe um fluxo do saber que, para se tornar possível de se converter em saber ensinado, por isso necessita haver uma compatibilização do sistema com seu entorno. Essa compatibilização presume dois aspectos ou relações - a relação com os especialistas (a academia) e a relação com a sociedade (pais). Esta relação pressupõe a proximidade do saber ensinado com o saber validado na academia e a distância com relação ao saber dos pais, como condição de valor dos conhecimentos ensinados na escola. A compatibilização do sistema didático com seu entorno, no que se refere aos saberes ensinados presume que os saberes possuem "vida" e que, portanto, envelhecem e tornam-se obsoletos, tanto moral com relação à sociedade, quanto banal com relação à academia e que, por envelhecer, devem constantemente restabelecer a compatibilização com o entorno, ou seja, restabelecer um fluxo entre o saber acadêmico e o saber ensinado (CHEVALLARD, 2005, p. 30 e 31). Assim, considerando o fluxo do saber entorno/sistema didático, Chevallard (2005) resume e explica que a transposição didática se configura da seguinte forma:

Un contenido de saber que ha sido designado como saber a enseñar, sufre a partir de entonces un conjunto de tranformaciones adaptativas que van a hacerlo apto para ocupar un lugar entre los objetos de enseñanza. El trabajo que transforma de un objeto de saber a enseñar en un objeto de enseñanza, es denominado la transposicion didáctica (CHEVALLARD, 2005, p. 45) 
Entende-se que a transformação de um saber para que se torne ensinável consubstancia-se na sua possibilidade ou condição de aprendizagem, pois "todo projeto social de ensino e aprendizagem se constitui dialeticamente com a identificação e a designação de conteúdos de saber como conteúdos a ensinar" que, embora explícitos em programas curriculares e nas tradições escolares, tais conteúdos preexistem ao movimento que designa qualquer saber como saber escolar (CHEVALLARD, 2005, p. 45). A partir do momento em que determinado conteúdo tenha sido designado como um saber a ensinar ele sofre um conjunto de transformações adaptativas que tornam o conteúdo designado apto a ocupar um lugar entre os objetos de ensino e por consequência de aprendizagem (CHEVALLARD, 2005, p. 45).

Dessa forma, "o saber-tal-como-es-enseñado, el saber enseñado, es necesariamente distinto del saber-inicialmente-designado-como-el-quedebe-ser-enseñado, el saber a enseñar" (CHEVALLARD, 2005, p. 16 e 17). Assim, o saber produzido pela "transposição didática" se constitui como um saber exilado de sua origem e separado de sua produção histórica na esfera de sua produção científica e, portanto, naturalizado (CHEVALLARD, 2005, p. 18).

A naturalização do saber, produto da "transposição didática", se realiza atendendo ao que Chevallard (2005) denomina de "preparação didática" que corresponde respectivamente aos seguintes requisitos:

- Dessincretização do saber;

- Despersonalização do saber;

- Programabilidade de aquisição do saber;

- Publicidade do saber;

- Controle social das aprendizagens

(CHEVALLARD, 2005, p. 69).

A dessincretização do saber corresponde a certo tipo de delimitação discursiva em que o saber é deslocado do seu contexto de produção científica e posto em um contexto didático para o ensino em que é, também, despersonalizado, ou seja, desvinculado de seu produtor (CHEVALLARD, 2005, p. 69-71). 
A programabilidade da aquisição das aprendizagens refere-se, na "preparação didática" ou textualização do saber, à normatividade da progressão no conhecimento e, por conseguinte, na aprendizagem, ou seja, o encadeamento didático em que se aprende ao mesmo tempo em que o conhecimento didatizado é operacionalizado em sua progressão, sequenciação. Desse modo, a programabilidade das aprendizagens pode ser entendida e operada a partir da aprendizagem de pré-requisitos no sentido de haver uma relação entre um conhecimento estudado - antigo - e um conhecimento a ser estudado - novo. (CHEVALLARD, 2005, p. 73-77).

Ainda situando o conhecimento e a aprendizagem na perspectiva de sua programabilidade, Chevallard (2005, p. 79) salienta que os objetos de ensino, na dialética antigo/novo sofrem um desgaste moral que pressupõe a sua renovação em um ciclo de ensino.

O processo de naturalização do saber e a sua condição para ser ensinado requer, ainda, que o saber em processo tenha como característica o fato de ser público, ou seja, autorizado publicamente em oposição à categoria de saber que seja pessoal. Essa condição, que naturaliza o saber despersonificando-o de seu produtor e programando-o quanto a sua aquisição, permite o controle social das aprendizagens, ou seja, a determinação do que deverá ser ensinado na escola enquanto conteúdo de saber (CHEVALLARD, 2005, p. 73).

Dois outros elementos permitem que se compreenda a perspectiva de aprendizagem a partir da "transposição didática", a "cronogenesis" e a "topogenesis", ambos relacionados diretamente à programabilidade das aprendizagens, ao seu controle e ao tempo didático. Na relação didática que une professor e aluno, é o professor o operador da "máquina didática", quem introduz objetos novos de saber à medida que um objeto anterior está na condição de ensinado, evitando, assim, a paralisação do programa curricular. Dessa forma, "cronogenesis" e "topogenesis" designam respectivamente tempo e lugar dos sujeitos e da aprendizagem de conteúdos de ensino na relação didática. Desse modo, na "cronogenesis" é o professor aquele que nessa relação sabe antes e mais sobre o conteúdo e, por isso, determina a sequência das aprendizagens, que introduz novos 
objetos de saber assim que certo objeto chega à obsolência ou não permite o avanço do programa curricular. O modo pelo qual se opera na "cronogenesis" é estruturado de forma progressiva, acumulativa e irreversível das aprendizagens na introdução de novos objetos de saber (CHEVALLARD, 2005, p. 81 e 82). A "Topogenesis" na relação didática refere-se ao lugar que o professor ocupa, seja com relação ao aluno, seja com relação ao objeto de saber (CHEVALLARD, 2005, p. 87).

Embora se tenha realizado pontuações acerca do conceito de transposição didática, considera-se, nesse trabalho, relevante a apropriação deste conceito no trabalho de Monteiro (2003), cuja investigação tinha por objetivo a mobilização de saberes por parte de professores de História em sua prática de ensinar. Para Monteiro (2003: 78-89), no conceito de transposição didática "Chevallard não considera em sua análise a dimensão educativa", que, em sua perspectiva se constitui como "um elemento estruturante fundamental para que se possa compreender o processo de constituição do saber escolar". O fato de Chevallard "manter a análise e seus referenciais dentro de um enquadramento científico" traz dificuldades para o reconhecimento do saber em seu "enraizamento sócio-políticocultural", tanto do saber acadêmico quanto do saber escolar. Para além dos elementos conflitantes, a autora concorda com o potencial conceitual da "transposição didática", porém enfatiza que tal potencial deve ser aliado às contribuições de outros autores enquanto instrumentos para a compreensão dos processos de ensino (MONTEIRO, 2003, p. 85).

Com apropriação diferenciada, Anhorn (2003) toma o conceito de transposição didática como centro de sua análise acerca dos Parâmetros Curriculares Nacionais e a sala de aula nas aulas de História e dos sujeitos da investigação (professores de História). A apropriação do conceito, realizado por Anhorn procura, a partir dos múltiplos diálogos, a articulação no ensino de História dos elementos de uma "transposição didática" externa, tomada no sentido da "noosfera" (Chevallard, 2005) e a "transposição didática" interna, aquela realizada pelo professor no ato de ensinar, na composição do seu texto de saber.

Os diálogos tomados por Anhorn (2003), muitos deles construídos a 
partir das críticas realizadas ao conceito de transposição didática, outros vinculados a questões epistemológicas e metodológicas da História, tomam como referência os aspectos de semelhança entre as ideias dos autores discutidos, objetivando a validação do conceito de transposição ao ensino da História, o qual a pesquisadora não nega a sua complexidade.

A articulação realizada por Anhorn (2003), entre a transposição didática externa e interna, teve como elemento concreto na investigação a problemática da identidade nacional enquanto conteúdo de ensino. Observamos, pelos seus caminhos de investigação, que este elemento se constituiu como o eixo articulador da discussão realizada pela pesquisadora.

Observa-se que embora possa ter como objetivo a aprendizagem, 0 conceito de transposição didática discutido até aqui perspectiva a aprendizagem sob o foco do ensino. Entretanto, interessa saber o que é aprender História sob o foco da transposição didática e que significados podem ter uma aprendizagem da História perspectivada por esse foco.

O primeiro ponto que chama a atenção na "transposição didática" quanto à perspectiva de aprendizagem histórica é a "preparação didática" (CHEVALLARD, 2005), a qual define os contornos do objeto ou conteúdos para que possam ser aprendidos no contexto escolar. Ou seja, uma operacionalização que reorganiza e retira o conhecimento histórico da sua condição de produção e de seu produtor, significando que as questões postas ao contexto de investigação não são as mesmas que as do contexto de aprendizagem. Essa operacionalização é realizada a partir da publicidade do saber e de seu objeto conteúdo, delimitando o que deve ser aprendido acerca da História, não como um saber que seja essencialmente científico, mas que é validado publicamente. Esse processo contribui para a descontextualização e despersonificação, em que o saber passa a ser legitimado e validado pela sua publicização. Assim, o saber histórico, para ser aprendido, deve ser programável e controlável. Desse modo, entende-se que uma aprendizagem histórica escolar implicaria, considerando sua possibilidade de sucesso, uma versão única e anônima sobre o passado.

Uma versão única e anônima da História como condição de sua aprendizagem não significa que essa versão seja à do interesse dos sujeitos 
envolvidos na relação didática, mas do interesse do sistema didático e do seu entorno, o que implica a pouca margem de ação dos sujeitos envolvidos no processo de aprendizagem, pois da perspectiva do professor não é ele quem faz a transposição didática (CHEVALLARD, 2005), apenas trabalha nela, pois a transposição pré-existe à sua ação. Na perspectiva do sujeito aprendente não há espaço para sua intervenção e participação, pois o lugar que lhe resta na relação didática é o da passividade, considerando a estrutura progressiva do tempo didático em que a aprendizagem deve ser isomorfa à progressão do texto de saber e à introdução de um novo conteúdo já dominado pelo professor nesse processo.

\section{Conhecimento e aprendizagem histórica: tensões entre transposição didática e literacia histórica}

Considerando a perspectiva de aprendizagem histórica da transposição didática, procura-se nesse tópico discutir e confrontar o conceito de transposição didática e literacia histórica, objetivando compreendê-las pelo que contêm de positivo para a aprendizagem histórica. Para isso, discutir-se-á: as diferenças substantivas entre a transposição didática e um conceito de literacia histórica. A literacia histórica é entendida nesse trabalho como um processo de alfabetização e letramento em História (LEE, 2006; BARCA, 2006).

Literacia histórica é tomada nesse tópico por conter entre seus elementos estruturadores uma perspectiva de aprendizagem histórica ancorada nas teorizações do filósofo da História Jörn Rüsen (2001) e, portanto considerando a especificidade do conhecimento histórico e sua epistemologia. A abordagem de Lee (2006) é construída em torno do conceito de "consciência histórica"2, vida prática e ciência especializada

2 Rüsen, (2001, p. 58), define a "consciência histórica" como "o modo pelo qual a relação dinâmica entre experiência do tempo e intenção no tempo se realiza no processo da vida humana", sendo para isso "determinante a operação mental com a qual o homem articula, no processo de sua vida prática a experiência e intenção no tempo". Desse modo, a "consciência histórica" se constitui como um trabalho intelectual realizado pelo homem para "tornar suas intenções de agir conforme com a experiência no tempo". 
(RÜSEN, 2001), em conjunto com investigações acerca das ideias históricas de jovens ingleses em escolarização. Os resultados da investigação realizada por Lee (2006) apontam que o entendimento da História para os jovens ingleses investigados não caminham no sentido de uma aprendizagem histórica, mas de "uma atividade dúbia e fútil", em que o passado não apresenta uma estrutura coerente.

Para Lee (2006), a compreensão e resolução do problema do ensino da História passam por uma "noção operacionalizável de literacia histórica" (LEE, 2006, p. 134), ou seja, de aprendizagem histórica.

No quadro de referência tomado por Lee (2006) para a construção de uma noção operacionalizável de literacia histórica, uma das principais referências é a Matriz Disciplinar da História ${ }^{3}$ construída por Rüsen (2001) e o conceito de consciência histórica, no sentido de que a compreensão do que seja a História deve ter uma relação com a vida prática dos sujeitos aprendentes, não se distanciando de elementos e regras metodológicas e práticas da ciência da História, permitindo aos sujeitos uma postura crítica em relação aos interesses presentes na vida prática, como fator de orientação dessa mesma vida. Desse modo, Lee (2006, p. 136) escreve que:

Uma primeira exigência da literacia histórica é que os alunos entendam algo do que seja história, como um compromisso de indagação com suas próprias marcas de identificação, algumas ideias características organizadas e um vocabulário de expressões ao qual tenha sido dado significado especializado: passado, acontecimento, situação, evento, causa, mudança e assim por diante (LEE, 2006, p. 136).

Essa perspectiva de literacia histórica pressupõe que se considere o conceito de evidência histórica no sentido de se compreender como o conhecimento histórico é possível, a ideia de empatia histórica, no sentido de se compreender de que modo as pessoas do passado pensavam e se

3 A Matriz Disciplinar da História compõe-se de duas partes: uma relacionada à vida prática com as carências de orientação e outra parte relacionada à ciência especializada, compondo-se do método histórico e das formas de apresentação. Para Rüsen (2001) o pensamento histórico emerge das carências de orientação da vida prática que passando pela ciência da História retorna a mesma vida prática reorientando-a ou abrindo novas carências. 
relacionavam com o mundo e a consideração de que os escritos sobre a História "não são cópias do passado", pois se referem às questões postas acerca de documentos do passado, que são narrativas, interpretações sobre casos do passado (LEE, 2006, p. 136). Desse modo, as considerações de Lee (2006), direcionadas a uma noção operacionalizável de literacia histórica, perpassam as perspectivas teóricas já discutidas sobre 0 pensamento histórico, das operações cognitivas do pensar historicamente, estando no rol da consideração das experiências do passado como algo que difere temporalmente das experiências do presente, de sua interpretação e de sua orientação. Observa-se que a operacionalização da ideia de literacia histórica defendida por Lee (2006) engloba a perspectiva da consciência histórica e de sua materialização sob a forma narrativa, bem como a perspectiva de um vocabulário que tenha significado na ciência da História como consideração sobre o passado.

Em conformidade com Rüsen (2001) e Oakeshott (2003), uma noção operacionalizável de literacia histórica, segundo Lee (2006) deve considerar que a História não se refere a todo o passado, mas ao passado que se faz presente como passado histórico, pois "há mais na história do que somente o acúmulo de informações sobre o passado" (LEE, 2006, p. 136).

Para além da perspectiva teórica acerca das considerações sobre o passado, Lee (2006) pontua que apenas atividades estimulantes em sala de aula, voltadas para a execução de ideias muito elementares sobre a História, são inúteis e falhas, pois se devem considerar, para a aprendizagem histórica, os "pré-conceitos que os alunos trazem para suas aulas de história" (LEE, 2006, p. 136). Assim, observa-se que uma consideração útil para a ideia de literacia histórica, que possa dar conta da aprendizagem histórica, deve perpassar um nível teórico do que seja a atividade de se pensar historicamente sob a perspectiva de uma função didática da História e as ideias prévias dos estudantes. Desse modo, a "compreensão de como as afirmações históricas podem ser feitas se constitui como uma condição necessária para a literacia histórica, mas não suficiente" (LEE, 2006: 140). Para tanto, Lee (2006) considera para uma noção operacionalizável de literacia histórica a construção de um grande 
quadro como uma estrutura utilizável do passado.

Considerar uma estrutura utilizável do passado não se refere ao espelhamento de fragmentos do passado, de uma série de eventos que devem ser ensinados ou assimilados como condição da construção individual e coletiva da identidade dos sujeitos como fator de sua orientação. Considerar uma estrutura desse modo é o mesmo que afirmar que o passado que deve ser ensinado e aprendido nos bancos escolares é um "passado prático" que justifique determinados interesses e se distancie de procedimentos tipicamente históricos (LEE, 2006, p. 140; OAKESHOTT, 2003).

Lee (2006: 140-146) propõe que "uma estrutura deve ser um ponto de vista geral de padrões de mudanças a longo prazo, não um mero esboço de história folheando picos do passado". Essa perspectiva, segundo Lee (2006) "deve ser ensinada rapidamente e sempre revisitada", no sentido de os alunos poderem "assimilar novas histórias em relação à estrutura histórica existente", construindo novos significados aos padrões de mudança histórica.

Considerar uma estrutura utilizável do passado não se refere ao estabelecimento de um rol de conteúdos que devem ser ensinados, mas ao entendimento de que os sujeitos estruturem suas ideias históricas, tendo como referência o passado que está no presente, as experiências do passado interpretadas e que possam servir como orientação da vida prática, como perspectiva de futuro como semântica dos tempos históricos (LOWENTHAL, 1998). Desse modo, uma estrutura utilizável do passado deve:

ser uma estrutura aberta, capaz de ser modificada, testada, aperfeiçoada e mesmo abandonada, em favor de algo mais, de forma que os alunos sejam encorajados a pensar e refletir sobre as suposições que fazem ao testar e desenvolver sua estrutura (LEE, 2006, p. 147).

Assim, uma estrutura utilizável do passado se constitui como um processo cognitivo que inclui, para além de conceitos, as experiências, a interpretação e orientação como fatores de aprendizagem. Esses elementos, 
constantes de uma "noção operacionalizável de literacia histórica" discutidos por Lee (2006), conduzem à compreensão de que a aprendizagem histórica se refere à consciência humana relacionada ao tempo, analisando o tempo para ser significativo, adquirindo a competência de dar sentido e significado ao tempo (RÜSEN, 1992).

Barca (2006) discute a ideia de uma literacia histórica tendo como referência as investigações de Lee (2006) e o conceito de "consciência histórica" (RÜSEN, 2001) e de uma investigação realizada com alunos do penúltimo ano do curso de licenciatura em Ensino da História da Universidade do Minho, Portugal. Entende-se, na perspectiva da investigação, que esses alunos serão futuros professores de História.

A investigação empreendida por Barca (2006) objetivava compreender os critérios pelos quais futuros professores de História decidem sobre versões históricas diferentes e de como fundamentam seus argumentos para a escolha de uma determinada versão.

Para Barca (2006) é no conceito de "consciência histórica" (RÜSEN, 2001) e no desenvolvimento desse tipo de consciência que o conceito de literacia histórica deve se fundamentar.

Considerando a perspectiva de que a "consciência histórica" ultrapassa a ideia de formação de uma identidade local, pois a orientação de cada um de nós exige, principalmente na atualidade, identificações múltiplas, desde local a global, Barca (2006: 95) entende que um conceito de literacia histórica deve ter como perspectiva a formação de "competências avançadas para saber ler o mundo que nos rodeia e também perspectivar de alguma forma o futuro, à luz de experiências humanas passadas".

Desse modo, Barca (2006) aponta que na perspectiva de uma literacia histórica "a aprendizagem é orientada para uma leitura contextualizada do passado a partir da evidência fornecida por variadíssimas fontes", pois considera que a História como conhecimento não está circunscrita a sentenças fixas sobre o passado na perspectiva de um passado único e verdadeiro, de uma narrativa universal. Esse argumento se sustenta principalmente pelo fato de se ter construções historiográficas 
diferentes e divergentes sobre as mesmas situações. Entretanto, Barca (2006, p. 96) pontua que "o reconhecimento de uma multiplicidade de narrativas não significa a aceitação indiscriminada de todas elas". Dessa forma argumenta:

Existem critérios específicos para justificar as versões históricas. Estes critérios são tacitamente usados para validar uma versão histórica contra versões de outro tipo, ficcionais ou produzidas sob compromissos de interesse prático (político, econômico, religioso). Mas tais critérios podem e devem também ser usados para comparar e avaliar o poder explicativo de versões históricas concorrentes (BARCA, 2006, p. 96)

Tomando esses elementos, Barca (2006) conclui que "será desejável que os alunos aprendam, de forma gradual, a comparar e a selecionar criteriosamente narrativas e fontes divergentes sobre um determinado passado".

Os resultados da investigação empreendida por Barca (2006) com futuros professores de História apontam que os critérios utilizados por estes sujeitos não divergem dos critérios utilizados por crianças e jovens, embora sejam mais sofisticados.

O conceito de "transposição didática" (CHEVALLARD, 2005) propõe uma aprendizagem, no caso, histórica, sobre outro modelo. Nesse conceito não há a perspectiva de se considerar o uso de fontes, muito menos de uma multiperspectiva ou de versões diferentes e divergentes sobre o conteúdo. O que propõe o conceito de transposição didática, ao que se pode inferir do processo de didatização que propõe - dessincretização, despersonalização, programabilidade, publicidade - é a narrativa única, na perspectiva do conhecimento histórico como uma verdade única. Observa-se que dessincretização e despersonalização são elementos contrários ao uso de fontes e de perspectivas diferenciadas sobre o passado. Se no conceito de "literacia histórica" (LEE, 2006; BARCA, 2006) pretende-se que os sujeitos aprendentes sejam capazes de ler o mundo, se orientar e desenvolver uma identidade que contemple várias perspectivas (característica de nossa época), realizando essa pretensão na perspectiva de uma cognição histórica 
situada $^{4}$ (SCHMIDT, 2009), de elementos racionais da Ciência da História, de sua objetividade metodológica e pensamento narrativo, a transposição didática não é capaz de proporcionar uma aprendizagem histórica que desenvolva a "consciência histórica" (RÜSEN, 2001), que se distancie de um "passado prático" (OAKESHOTT, 2003), exemplar, único, pois, conforme já apontado, sua preocupação não reside na aprendizagem, mas no ensino, na transmissibilidade de um saber histórico na qualidade de resultados e afirmações sobre o passado.

\section{Conhecimento e aprendizagem histórica: transposição didática e literacia histórica na perspectiva de professores de história}

A partir das tensões evidenciadas entre o conceito de transposição didática e literacia histórica como possibilidades nas quais o conhecimento histórico e sua aprendizagem podem ser explicitados no contexto escolar, discute-se nesse ponto em que perspectiva tais conceitos se explicitam nas concepções de aprendizagem da história de professores de história.

As tensões entre a transposição didática e a literacia histórica podem ser evidenciadas quando os professores entrevistados dizem que:

(...) que é a partir da história você tem um vislumbre do mundo diferenciado (...) a partir desse vislumbre, também diferenciado, você vai ter um ensino diferenciado. A partir do ponto de vista histórico que o aluno recebe ele vai ter a condição de olhar para o mundo de forma diferente (...) trago a história para o cotidiano, às vezes soa até mesmo factual. Porém, sempre enfatizando o lado crítico, o lado da mudança que $o$ aluno pode a partir da história mudar alguma coisa (...). A história na realidade não se encontra dentro da sala de aula. A sala de aula é um local de diálogo e relato, não onde se aprende história. Ela é aprendida no cotidiano (PROFESSOR RUI, 2010).

Aprender história é analisar a sociedade e conseguir compreender que ela é o resultado de um processo, do

4 Schmidt (2009) ao investigar a aprendizagem histórica nos Parâmetros Curriculares Nacionais aponta que a aprendizagem histórica nesse documento não está situada na ciência da História, mas nos referenciais da Pedagogia e Psicologia do Desenvolvimento. 
trabalho e das lutas realizadas pelos homens em grupos. (PROFESSOR PLÍNIO, 2010).

Aprender história é conhecer o passado para poder fazer relações desse conhecimento com o presente. De acordo com a experiência em sala de aula, o significado que percebo é, primeiramente, sanar a curiosidade, e num segundo momento, comparar o passado com o presente. (PROFESSORA MARINA, 2010).

Aprender história é fornecer subsídio para que o aluno tenha um chão para pisar, dar ferramentas para ver o mundo, lendo o mundo que o cerca pode-se tomar uma decisão. Todo o conhecimento, de certa forma, é histórico (PROFESSOR JOSÉ MARIA, 2010) $)^{5}$.

Conforme se observa quanto ao processo de didatização da História pela transposição didática na perspectiva de um conhecimento já dado, na visão do professor Rui, há muito mais do que a História como algo dado, há escolhas axiológicas, conceituais e de entendimento que, não se situando diretamente na perspectiva de uma teoria da História, se distancia, em parte, da perspectiva advinda da transposição didática. Exceto o professor José Maria, os outros professores situam a aprendizagem da história tendo como premissa o conhecimento do passado para relacioná-lo com o presente e não o seu contrário.

Relacionar passado ao presente e não presente a passado indica uma perspectiva de ensino e aprendizagem da história pautada na transposição didática, infere-se dessa perspectiva que o professor no seu processo de didatização procura relacionar o conteúdo ao presente do aluno e não o presente do aluno como uma construção histórica.

O significado dado pelos sujeitos à História, bem como o seu conhecimento, comprometido com o processo de didatização pela "transposição didática", se apresenta na fala de professores quando dizem que os conteúdos não se articulam com a vida dos alunos.

Eu sempre levo a história para um lado prático e para um lado divertido, então, trago a história para o cotidiano, às vezes soa até mesmo factual. Porém, sempre enfatizando o

5 Sujeitos investigados no processo de pesquisa da dissertação "Concepções e significados da aprendizagem histórica na perspectiva da experiência de professores de história". 
lado crítico, o lado da mudança que o aluno pode a partir da história mudar alguma coisa. Isso causa o interesse do aluno e traz ele para a realidade histórica e para a vida. (PROFESSOR RUI, 2010)

Tem coisas que não dá, que fica, não que não dá, mas fica difícil de relacionar (PROFESSOR PLÍNIO, 2010)

Sim, às vezes eu acho não com a vida cotidiana deles, não com o dia-a-dia, mas com o que eles observam, com o que falam os pais em casa, com o que passa na TV, é daí que eu consigo fazer uma relação, não com o dia-a-dia deles. (PROFESSORA MARINA, 2010)

(...) tem uns conteúdos que, ora, fica difícil de estabelecer uma relação (...) quando eu posso partir da vida deles para o conteúdo a aula é muito mais fantástica, melhor. Agora, tem uns conteúdos que não tem como fazer uma relação com a vida do aluno (PROFESSOR JOSÉ MARIA, 2010).

Outro ponto que chama a atenção no conceito de transposição didática é com relação aos entendimentos sobre o objeto de ensino e aprendizagem da História. Compreende-se que não é pertinente deslocar o conceito de sua origem - as matemáticas - entretanto, observa-se pelas investigações de Monteiro (2002) e Anhorn (2003) que esse deslocamento já ocorre. Desse modo, é preocupante assumir que o objeto de ensino e aprendizagem da História possa ser dessincretizado, descontextualizado e despersonificado, entendendo que tal objeto corresponde "às experiências humanas no fluxo do tempo" (THOMPSON, 1987). Ademais, entendendo que o que dá acesso a essas experiências são as questões colocadas às fontes históricas, primárias ou secundárias, passíveis de interpretação a partir do método histórico, a relação com o conhecimento sempre passa pela interpretação dos sujeitos.

A transposição didática tal como se apresenta, não só vitimiza o objeto de ensino e por consequência objeto de aprendizagem, pelo tempo didático, mas pela sua operacionalização como um todo, significando que a aprendizagem da História não deve ser pautada pela ciência de referência, mas por uma adaptação dos produtos dessa ciência ao "sistema didático" como condição do sucesso da aprendizagem e progressão do programa de ensino. Enfim, a aprendizagem histórica a partir da transposição didática 
não reconhece o referencial da racionalidade histórica para a aprendizagem, mas os resultados da investigação histórica simplificados como fatos sequenciados do passado.

Desse modo, inquire-se sobre o que dá sentido à aprendizagem da História para os sujeitos aprendentes no contexto escolar a partir da transposição didática. Entende-se pelo exposto acerca do conceito de "transposição didática", que o sentido da aprendizagem da História não está referido à racionalidade da História, mas a objetivos externos a esta racionalidade, localizados em instância exterior aos interesses dos sujeitos escolares.

A fala dos professores entrevistados aproxima-se do conceito de literacia histórica na medida em que objetiva o ensino e a aprendizagem da história na perspectiva de fornecer "subsídios", "ferramentas" e "chão para o aluno pisar", da possibilidade de se partir da vida do aluno o que significa pensar o processo de ensino e aprendizagem da história na perspectiva de seu letramento.

\section{Considerações}

As pontuações sobre o conceito de transposição didática conduz a consideração de que o conhecimento histórico nessa perspectiva didática não considera os sujeitos da aprendizagem e nem o seu mundo, pois nos processos escolares de ensino não considera a especificidade do conhecimento histórico e a sua aprendizagem. Tomar a aprendizagem histórica por um conceito de literacia histórica torna a aprendizagem da história significativa e relacionada ao mundo vivido pelos sujeitos. Apesar de que tomar a aprendizagem histórica pela perspectiva da literacia histórica seja positivo, não é uma realidade nas concepções dos professores de história investigados, inferindo-se de seus relatos apenas alguns elementos. Entretanto não é seguro afirmar que os professores situam a aprendizagem da história por um conceito de transposição didática, dado que os elementos dessa concepção de conhecimento escolar não se 
apresentam totalmente nos relatos dos professores. Evidentemente considera-se nesses relatos uma tensão entre a natureza específica do conhecimento histórico e a sua didatização transpositiva. Essa constatação pode ser explicada pela cultura escolar, tal qual conceitua Forquin (1993) e pela manutenção ou existência de um "código disciplinar" (CUESTA FERNANDEZ, 1997; URBAN, 2009).

Evidenciada a tensão existente acerca da aprendizagem histórica entre a transposição didática e a literacia histórica e tomando o conhecimento histórico nos processos de ensino e aprendizagem pela sua natureza específica, considera-se pertinente, senão razoável, o investimento nos processos de formação inicial e continuada de professores de história, situar o ensino e a aprendizagem da história a partir da sua especificidade.

\section{Referências}

ANHORN, C. T. G.. Um objeto de ensino chamado História: a disciplina de História nas tramas da didatização. Tese (Doutorado em Educação) Departamento de Educação, Pontifícia Universidade Católica, Rio de Janeiro, 2003.

BARCA, I. Literacia e consciência histórica. Educar em Revista. Curitiba, n.164, 2006 (Dossiê Educação Histórica).

CHEVALLARD, Y. La transposición didáctica: del saber sabio al saber enseñado. 3 ed. Buenos Aires: Aique: Grupo Editor, 2005.

CUESTA FERNANDEZ, R. Sociogénesis de una disciplina escolar: la História. Barcelona: Ediciones Pomares-Corredor, 1997.

FORQUIN, Jean-Claude. Escola e cultura: as bases sociais e epistemológicas do conhecimento escolar. Porto Alegre: Artes Médicas, 1993.

GRENDEL, M. T. De como a didatização separa a aprendizagem histórica de seu objeto: estudo a partir da análise de cadernos escolares. Tese (Doutorado em Educação) - Universidade Federal do Paraná, Curitiba, 2009.

LEE, P. Em direção a um conceito de literacia histórica. Educar em Revista. Curitiba, n. 164, 2006. (Dossiê Educação Histórica).

LEITE, M. S. Contribuições de Basil Berstein e Yves Chevallard para a discussão do conhecimento escolar. Dissertação (Mestrado em Educação) Departamento de Educação, Pontifícia Universidade Católica, Rio de Janeiro, 2004. 
Recontextualização e transposição didática: introdução à leitura de Basil Bernstein e Yves Chevallard. Araraquara: Junqueira \& Marin, 2007.

LOPES, A. C.; MACEDO, E. Currículo: debates contemporâneos. São Paulo: Cortez, 2002.

LOWENTHAL, D. Como conhecemos o passado. Projeto História, São Paulo: PUCSP, n. 17, 1998. p. 63-201

MONTEIRO, A. M. Ensino de História: entre saberes e práticas. Tese (Doutorado em Educação) - Departamento de Educação, Pontifícia Universidade Católica, Rio de Janeiro, 2002.

OAKESHOTT, M. Sobre a História e outros ensaios. Rio de Janeiro: Liberty Classics, TopBooks, 2003.

RÜSEN, J. El desarrollo de la competencia narrativa em el aprendizaje histórico. Una hipótesis ontegenética relativa a la consciência moral. Revista Propuesta Educativa. Buenos Aires, Ano 4, n. 7, p. 27-36. oct. 1992. . Razão histórica. Teoria da história: os fundamentos da ciência histórica. Brasília: UnB, 2001. Como dar sentido ao passado: questões relevantes de metahistória. Revista História da Historiografia, UFOP, n. 2, 163-209, 2009. Aprendizado histórico. In: SCHMIDT, M.A.; BARCA, I.; MARTINS, E. R. Rüsen e a educação histórica. Curitiba: Ed. UFPR, 2010a. Experiência, interpretação, orientação: as três dimensões da aprendizagem histórica. In: SCHMIDT, M. A.; BARCA, I.; MARTINS, E. R. Rüsen e a educação histórica. Curitiba: Ed. UFPR, 2010b. Narratividade e objetividade nas ciências históricas. In: SCHMIDT, Maria A. M.; BARCA, I.; MARTINS, E. R. Rüsen e a educação histórica. Curitiba: Ed. UFPR, 2010c.

SCHMIDT, M. A. M. dos S. Concepções de aprendizagem histórica presentes em propostas curriculares brasileiras. História Revista UFG, Goiânia, v. 14, n. 1, p. 203-213, jan/jun, 2009.

THOMPSON, Edward Palmer. A formação da classe operária inglesa. Rio de Janeiro: Paz e Terra, 1987.

URBAN, A. C. Didática da História: percursos de um código disciplinar no Brasil e na Espanha. Tese (Doutorado em Educação) Universidade Federal do Paraná, Curitiba, 2009.

Enviado pelo autor em 07 de Maio de 2012.

Aprovado em 19 de Junho de 2012. 